\title{
Language use in the classroom: Identity in classroom discourse
}

\author{
Muhlisin \\ Universitas Muhammadiyah Jember \\ Pratiwi Andrini \\ MTs. Al-Badri
}

\begin{abstract}
This study concerned group of Indonesian EFL learners' perceptions regarding the use of Indonesian (L1) and English language (L2) by their teachers in the classroom. In particular, the study aimed to unravel how these learners perceived the use of their L1 and L2 during the course of English instruction in the classroom and how their perceptions might have been shaped by different aspects of "identity construction" to which they were oriented. Data were gathered through administering a questionnaire to one hundred seventy-three adult Indonesian EFL learners. Analysis of the learners' responses suggested that they maintained different perceptions with regard to the use of their L1 and L2 and that their perceptions may be subsumed into two broad categories, each of which reflects the differences in their perceptions. Factors that might have affected the learners' perceptions were then critically discussed in the light of identity theory in the context of L2 pedagogy. In particular, the theory suggests that different aspects of identity construction to which learners are oriented affect their perceptions of the use of theirL1 and L2 in the classroom. Further, these different aspects of identity construction may also affect how learners are likely to respond to the use of an L1 and L2 in the classroom (and beyond).
\end{abstract}

Keywords: English as a foreign language (EFL), language use, identity theory in L2 pedagogy

\section{Introduction}

There have been quite a large number of studies conducted to reveal patterns of interaction between L2 teacher and learners in L2instructional contexts (e.g., Cullen, 2002; DaileyO'Cain \& Liebscher, 2009). One of the aims of these studies is usually to unravel interactional patterns between the teacher and learners that may prove effective or ineffective in facilitating the development of the learners' communicative competence in a target language. However, to date relatively little has been done to investigate how different aspects of "identity construction" (see Zimmerman, 1998) to which learners are oriented may affect their perceptions of any interactional patterns in the classroom (and beyond). The present study, therefore, attempted to address this issue. In particular, the study aimed to explore how a group of adult Indonesian EFL learners perceived the use of their L1 (Indonesian) and L2 (English) during the course of L2instruction in the classroom and how their perceptions may have been shaped by their orientation to different aspects of identity construction.

In his critical review of research on classroom interactional patterns between L2 teacher and learners, Richards (2006) contended that "shifts in the orientation to different aspects of identity produce distinctively different interactional patterns" (p. 52, emphases added). In 
the light of identity theory (see e.g., Gee, 2008; MacLure, 1993; Zimmerman, 1998), teachers and learners are believed to maintain particular beliefs, perceptions and values regarding the 'best' form of classroom teaching and learning, including the extent of which their L1 and L2 ought to be used during the course of instruction in the classroom. Hence, teachers and learners' preferences on particular use of a language constitutes a significant aspect on which their identity is constructed; be it default, situated, or transportable (Richards, 2006).

In this context of research, the concept of identity is usually used to refer to cultural, ideological, or personal beliefs, values, and attitudes toward the use of an L1 and L2(Gee, 2008; MacLure, 1993; Richards, 2006; Zimmerman, 1998), and in line with the context of the present study, the concept of identity is classified and defined as follows:

- Default identity derives entirely from culturally-based inheritance which causes a desirable attitude towards an L1 and quite undesirable attitude towards an L2.

- Situated identity, on the other hand, derives from ideological orientation to situating an L1 and L2 equally on the basis of contexts or situations.

- Meanwhile, transportable identity refers to personal alignment of "self" as an L2 user and thus promotes desirable attitude towards the L2.

With regard specifically to the institution where the study was conducted, teaching by using both L1 (Indonesian) and L2 (English) has long constituted the standard norm. Nonetheless, the degree of which these two languages are used in the classroom varies between teachers. In addition, different learners appear to respond differently to the teachers' different frequency in using the two languages in the classroom; that is, one group of teachers may prefer using much more Indonesian to English, while another group may prefer using English much more frequently to Indonesian. This sort of inconsistencies are presumably related to the degree of communicativeness of which the L2 is used in the classroom. For example, where a teacher considers that L2needs to be used intensively in the classroom to create the condition in which learners can get exposed intensively to its use in communicative context, he/she may reckon that using L2 is indispensable or even mandatory. Furthermore, the teacher may also require that learners use the L2while communicating in the classroom as well. By contrast, where the teacher perceives that the use of learners' native language is particularly helpful, he/she may not be so reliant on the exclusive use of the L2 and allows learners to use their native language, albeit judiciously.

Stemming from this sort of discrepancies concerning "best practices" for using L1 and L2 in the classroom, it is assumed that the extent of which L1 and L2 are used by teachers in the classroom will further affect learners' attitude towards the classroom teaching and learning. Some groups of learners may expect a maximum use of L2 in the classroom and thus may further indicate a positive attitude towards the classroom atmosphere, while others may consider that the use of L1 will, to a great extent, be very helpful. The present study attempted to initially explore these issues.

\section{Research questions}

In particular, the present study attempted to seek answers to the following research questions: 
1) How do adult Indonesian EFL learners perceive different degrees of which their L1(Indonesian) and L2 (English) are used by their teachers in the classrooms?

2) What aspects of identity are likely to be maintained by these learners as reflected by their perceptions of the teachers' use of L1 and L2?

The present study is motivated by an assumption that learners' perceptions of which their L1 and L2ought to be used by their teachers during the course of instruction in the classroom are largely influenced by their orientation to different aspects of identity construction, be it default, situated, or transportable (see Richards, 2006; Zimmerman, 1998).

\section{Methodology}

This is an initial exploratory study using a qualitative approach to collecting and analysing data. To collect the data, a one-shot open-ended questionnaire was administered to different groups of adult Indonesian EFL learners learning English in a private university based in Jember, East Java, Indonesia. To triangulate learners' responses to the questionnaire, classroom observations were also conducted. The observations were mainly intended to know, in general, how or to what extent theL1 and L2 were used by teachers in the classroom and how learners appeared to respond to the use of the two languages by the teachers.

\section{Research Participants}

Four teachers participated in the study. These teachers provided a source of information as to the extent of which an L1 and L2 were naturally used in the classroom. These teachers were first informed about the purpose of the study and subsequently agreed to voluntarily participate in it. Among the four teachers, two of them taught Academic English Writing course, while the other two teachers taught English speaking skills. Like the majority of English teachers in Indonesia, these four teachers are Indonesian and are non-native speakers of English. With that being said, the teachers hold professional background and qualification in the field of English language teaching from Indonesian universities and have had years of experience in teaching English to different groups of English language learners in Indonesia.

With regard to the learners, a group of a hundred and seventy-three (173) Indonesian adult learners learning English with the four teachers were involved in the study. These learners were also informed about the purpose of the study. Their consent was obtained before they participated in the study. It is worth noting that both the teachers and the learners had a lot in common, especially in terms of their L1/native language, and the fact that both of them shared the same L1made it easier for them to fall back to the use of L1 whenever they encountered difficulty in communicating using the L2 (English).

\section{Data}

In line with what has been discussed above, the study thus included both participant and nonparticipant reports. The participant reports were obtained through administering a questionnaire to the learners. Then, the learners' responses to the questionnaire were triangulated with the results of the classroom observations. As such, classroom observations helped to verify whether the learners' responses in the questionnaire truly reflected with their behaviour in the real context of classroom teaching and learning.

\subsection{Questionnaire}


"[A] good deal of precision and clarity" constitute one of the most important criteria of good questionnaire (McDonough \& McDonough, 1997, p. 171), and one of the most important aspects that ensures precision and clarity is the use of language. Thus, Indonesian was used in the questionnaire to ensure the clarity of the questions asked along with the precision of the responses given by the learners. In the questionnaire, the questions asked were mainly about how the learners liked their teachers to teach them in the classroom, i.e. if they liked the teachers to use English more than Indonesian, or use Indonesian more than English, or use both Indonesian and English somewhat equally. The learners were then asked to provide their reasons to justify their answer to the first question. In this way, the questionnaire given to the learners were open-ended and did not specify what responses to be given.

\subsection{Observation}

The observations were conducted in four classes taught by the four teachers. The observations were mainly intended to see how the teachers used the L1 and L2 in the course of giving instruction and how the learners appeared to respond to it.

\section{Findings}

\subsection{Question 1}

As regards the learners' responses to the questionnaire, it shows that only ten (5.8\%) out of a hundred and seventy-three (173) believed that more English than Indonesian needed to be used by the teachers, while the remaining (a hundred and sixty-three or 94.2\%) believed that it was necessary that both L1 and L2 were used somewhat equally by the teachers. None of the learners believed that Indonesian should have been used more than English by the teachers in the classroom.

Table 1. Learners' perceptions regarding the use of L1 and L2 use in the classroom

\begin{tabular}{l|ccc}
\hline OPTIONS & More English & English and Indonesian & More Indonesian \\
\hline $\begin{array}{l}\text { Number of } \\
\text { Learners }\end{array}$ & $10(5.8 \%)$ & $163(94.2 \%)$ & $0(0 \%)$ \\
\hline
\end{tabular}

\subsection{Question 2}

Despite some similarities among the learners regarding their perceptions, many of these learners had their own (different) reasons underlying their perceptions. Based on the learners' responses to the questionnaire, it is argued that their perceptions conformed to different aspects of identity construction to which they were oriented. That is, a hundred and sixty three learners $(94.2 \%)$ maintained situated identity and ten learners $(5.8 \%)$ maintained transportable identity, and no learners (0\%) maintained default identity per se (see above for the operational conceptualization of these three types of identity). Further discussion of the findings is provided in the next section.

\section{Discussion}

In the light of Vygotskyan paradigm, talks constitute the medium which facilitate learning. That is, teachers, who are usually regarded as the more 'significant others', can help learners develop new skills or knowledge by means of communication using a language. Since the 
skills which most learners intend to develop in the context of foreign language teaching and learning are related to their ability in using the target language accurately, fluently and appropriately in authentic communication, it may be argued, therefore, that the target language should be used as much as possible by the teacher when communicating with his/her learners. Likewise, learners are also expected to practise using the target language as frequently as possible in the classroom. However, Harmer (2007, p. 3) asserted that when both teachers and learners encounter difficulty in communicating ideas with each other for using the target language, it would be "foolish" to deny using their first language. In such a case, first language may facilitate the learning process. The findings of this study agree with such notion that none of the learners believed the target language (L2/English) should be the only language used in the classroom, although they have different opinions as to how much and in what situation the native language (L1/Indonesian) ought to be or need to be used. This issue, however, is beyond the scope of the present study.

Notwithstanding, with respect to the extent and demand of the teacher use of L1, there were only a very small number of learners (10 learners) who reckoned that L1 should have been used only when problems in communication were encountered. With regard to their attitude towards the use of L2, these 10 learners were obviously more 'tolerant with ambiguity' (Johnson, 2001, p. 141). That is, although these 10 learners confessed that they too faced problems in understanding certain 'communicative messages' that the teachers expressed using the L2, they, however, would not easily get discouraged by such experience. Furthermore, as seen from their performance during or outside the course of instruction, these 10 learners were far more proficient in using the L2(English) as compared with those who easily got distracted with their 'sense of ambiguity' when experienced a lack of understanding to the teachers' use of the L2. In general, these findings lend support to a study conducted by Naiman et al. (1978 cited in Johnson, 2001, 142) in which learners who tolerate more to the use of L2, even if they cannot understand all of the words expressed in the L2, are better language learners than those do not.

These 10learners'perceptionsalso have something in common with other learners who learned a foreign language in other foreign language instructional contexts. Brooks-Lewis (2009), for instance, challenges the exclusion use of L1 based on the findings of his research. In his study, Brooks-Lewis (2009) showed that adult learners' perceptions of the incorporation of their L1 in FL teaching and learning were "remarkably positive, with a variety of reasons given as to why adult learners felt that the inclusion of their L1 in the classroom and its incorporation in the teaching and learning experience had been beneficial and how it had made the learning process not only meaningful but pleasurable" (p. 216).

As regards the aspect of identity construction to which the ten (10) learners were oriented, it is argued that it might be subsumed into the type of 'transportable identity' (Richards, 2006), for they maintained a quite strong alignment of themselves as English language users and maintained highly desirable attitude towards L2(Zimmerman, 1998). On the other hand, the aspect of identity construction to which the majority of the learners (a hundred and sixty three) were oriented, however, might be subsumed into 'situated identity' in that they situated the use of their first language and English language only on the basis of contexts or situations (ibid.).

\section{Conclusion}

Different learners maintain different perceptions with respect to the use of L1 and L2 in the classrooms by their teachers and that their perceptions appear to relate to different aspects of 
identity construction to which they are oriented. Further analysis towards the aspects of identity construction also reveals that learners who maintain transportable identity (i.e. those who are tolerant to the ambiguity) are very likely to develop high proficiency in using the L2 more successfully in comparison to other learners in this study. However, it is necessary to note that the main issue raised in this study is not on whether L1 should be or should not be used in the classroom. Rather, it constitutes a preliminary attempt to understand how learners perceived the use of L1 and L2 in the classroom. Further studies may need to look further into how L1 and L2 can be used judiciously to help learners learn L2 more effectively (cf. Schweers, 1999; White \&Storch, 2012; Cook, 1999; Carson \& Kashihara, 2012).

Finally, although this study has, to some extent, revealed different perceptions of learners with regard to L1 and L2 use, it does not address the epistemological domains underlying the emergence of the perceptions. Hence, further studies may want to deal with these epistemological domains, and may also delve further into the ontological ones, as well.

\section{References}

Brooks-Lewis, K. A. (2009). Adult Learners' Perceptions of the Incorporation of Their L1 in Foreign Language Teaching and Learning. Applied Linguistics, 30(2): 216-235.

Carson, E., \& Kashihara, H. (2012). Using the L1 and the L2 Classroom: The students speak. The Language Teacher, 36(4): 41-48.

Cook, V. (1999). Going Beyond the Native Speaker in Language Teaching. TESOL Quarterly33(2): 185-209.

Cullen, R. (2002). Supportive Teacher Talk: the importance of F-Move. ELT Journal, 56(2): $117-127$.

Cook, V. (1999). Going Beyond the Native Speaker in Language Teaching. TESOL Quarterly, 33(2): 185-209.

Dailey-O'Cain, J., \& Liebscher, G. (2009). Teacher and Student Use of the First Language in Foreign Language Classroom Interaction: Functions and Applications. In M. Turnbull \& J. Dailey-O'Cain (Eds), First Language Use in Second and Foreign Language Learning (pp. 131-144). Bristol: Multilingual Matters.

Harmer, J. (2007). How to teach English. Harlow: Pearson.

Gee, J.P. (2008). Social Linguistics and Literacies: Ideology in discourses (3rd ed.). Abingdon and New York: Routledge.

Johnson, K. (2001). An introduction to foreign language learning and teaching. Harlow: Pearson.

MacLure, M. (1993). Arguing for yourself: Identity as an organizing principle in teachers' jobs and lives. British Educational Research Journal, 19, 311-322.

McDonough, J. \& McDonough, S. (1997). Research methods for English language teachers. London: Arnold.

Richards, K. (2006). Being the Teacher: Identity and Classroom Conversation. Applied Linguistics, 27(1): 51-77.

Schweers, C. W. Jr. (1999). Using L1 in the L2 classroom. English Teaching Forum, 37(2): 6-9.

White, E. \&Storch, N. (2012). En Français S'il Vous Plait: A longitudinal study of the use of the first language (L1) in French foreign language (FL) classes. Australian Review of Applied Linguistics, 35(2): 183-202.

Zimmerman, D. H. (1998). Discoursal Identities and Social Identities. In C. Antaki \& S. Widdicombe (Eds.), Identities in Talk (pp. 87-106). London: Sage. 